\title{
The Mechanical and Comfort Properties of Viscose with Cotton and Regenerated Fibers Blended Woven Fabrics
}

\author{
Abdul BASIT ${ }^{1 *}$, Wasif LATIF ${ }^{2}$, Sajjad Ahmad BAIG ${ }^{3}$, Abdur REHMAN ${ }^{4}$, \\ Muhammad HASHIM ${ }^{3}$, Muhammad ZIA UR REHMAN ${ }^{3}$
}

\author{
${ }^{1}$ Department of Yarn Manufacturing, National Textile University, Sheikhupura road, 37610, Faisalabad, Pakistan \\ ${ }^{2}$ Nishat Textile Mills, Nishatabad, 38610, Faisalabad, Pakistan \\ ${ }^{3}$ Department of Business Administration, National Textile University, Sheikhupura road, 37610, Faisalabad, Pakistan \\ ${ }^{4}$ Department of Textile Processing, National Textile University, Sheikhupura road, 37610, Faisalabad, Pakistan \\ crossref http://dx.doi.org/10.5755/j01.ms.24.2.18260
}

Received 27 May 2017; accepted 05 July 2017

\begin{abstract}
The increasing demand of cotton and low production rate to fulfil the world requirements has boosted the production of regenerated cellulose based fibers. The purpose of this work was to compare the performance and comfort properties of regenerated cellulose fibers. For this purpose, cotton, viscose, tencel, modal, bamboo and viscose fibers were taken. Cotton and viscose of $100 \%$ and blends (50:50) of viscose with cotton and regenerated fibers were taken. Normal yarn of count 20 tex was made and plain woven fabric samples were made and then pre-treated. The Warp-wise and weft-wise tensile and tear strengths were recorded. In addition, the tests of air-permeability, moisture management and thermal resistivity were performed It is found that the viscose:tencel and viscose:modal blends give better mechanical and comfort properties than all other blends. Also, it is found that viscose:cotton blend gives the lowest mechanical and comfort properties out of all studied fabrics. It is concluded that viscose makes more suitable blend with tencel and modal which outperforms in mechanical and comfort properties than other blends.
\end{abstract}

Keywords: viscose, regenerated blends, mechanical properties, comfort properties, woven fabrics.

\section{INTRODUCTION}

Cotton fabric is common in our lives. So this crop has a gigantic load to fulfil the increasing demand of the world. Denim industry is a big industry that relies on cotton. On the other hand, unfortunately, conventional cotton is a notoriously "dirty" crop containing lot of dust even after so much processing steps. Furthermore, only $2.5 \%$ of the world's cultivated land is cotton, which is not sufficient with growing needs of drastically increasing world population. In addition to this, the increasing demand of cotton gave rise to the use of herbicidal and with pesticidal treatment covering $16 \%$ usage for a single major crop to nurture it in bulk quantity with less damages but it is being paid at the cost of human health like risks of asthma skin allergies and even cancers [1].

Growth of organic cotton has been encouraged for last few years, which does not require any treatment of pesticides. These organic farming methods use natural fertilizers, like compost and animal manure, that recycles the nitrogen already in the soil rather than adding more, which reduces both pollution and $\mathrm{N}_{2} \mathrm{O}$ emissions [2]. As the growth of Organic cotton is limited to cope with needs of the industry so better accompaniments are also required to keep pace with required demand. Cellulosic regenerated fibres have come a long way in this respect which serves as environment friendly fibres as they come from nature and go back to nature. They serve as highly comfortable and breathable fibres and possess properties very like cotton and can serve as better substitute to cotton. Modern trends and growing demands have forced scientists to search for such fibers that can serve to expand wide range of applications in textile industry [3].

The regenerated cellulosic fibers, such as viscose, modal and lyocell, combine the advantages of natural and synthetic fibers and offer unique properties in textile. Their production is environment friendly and pollution-free. The viscose production line at Lenzing AG, Austria, which is based on dissolution of cellulose, is a simple and intrinsically clean route to regenerated fibers [3].

Three generations of regenerated cellulose fibres, such as viscose, modal, Bamboo and Tencel fibres are among the most important fibres from the point of textile and environmental aspects due to the natural structures and properties. Different production process and production conditions for conventional viscose, modal, Bamboo and new Tencel fibres cause differences in the structure of the fibres in spite of the same chemical compositions [3].

The microstructure and thermal properties of Tencel, viscose and modal fibres were analysed using DSC, TG and FTIR. The FTIR spectral analysis showed that Tencel was highly crystalline than others and was composed of crystalline cellulose II and amorphous cellulose. In this way, Tencel was found to have higher thermal stability than viscose and modal [4]

Viscose is a solution of cellulose xanthate made by treating a cellulose compound with sodium hydroxide and carbon disulphide. By products include sodium thiocarbonate, sodium carbonate, and sodium sulphide. The

\footnotetext{
* Corresponding author. Tel.: +92-300-7674984; fax: +92-41-9230098.

E-mail address: basit_ntu@yahoo.com (A. Basit)
} 
viscose solution is used to spin the fibre viscose rayon, or rayon, a soft man-made fibre commonly used in dresses, linings, shirts, shorts, coats, jackets, and other outer wear. It is also used in industrial yarns (Tire- cord), upholstery and carpets [5].

Studies exist in which viscose is blended with polyester to have increased thermo-physiological properties $[6,7]$ but polyester is not a sustainable fiber [8]. Some references studied the viscose fabrics and compared different properties with cotton. They found that the different properties of cotton and viscose are comparable [9-11]. Cotton is although a natural fiber but it requires a lot of water and pesticides [8]. Available studies are limited in which viscose is blended with modal fiber [12]. However, up to our information, the blends of viscose with regenerated fibers have not been reported. This work is the study of viscose fibers blended with cotton and other regenerated fibers (tencel, modal, bamboo) to explore the mechanical and comfort properties of 50:50 blended fabrics. The purpose is to find the suitable viscose blend with the regenerated fibers so as to replace cotton.

\section{MATERIALS AND METHODS}

\subsection{Materials}

In order to conduct study, cotton as natural cellulose fiber was used. Regenerated fibers included viscose, tencel, modal and bamboo. $100 \%$ viscose and $100 \%$ cotton and viscose blended with other regenerated cellulose fibers (50:50) were used. Properties of tencel, cotton and other regenerated fibers are given in Table 1.

Table 1. Specifications of fibers: cotton, tencel, modal, viscose and bamboo. Rd stands for degree of reflectance, $+b$ stands for yellowness

\begin{tabular}{|l|c|c|c|c|c|}
\hline \multicolumn{1}{|c|}{ Parameters } & Cotton & Tencel & Modal & Viscose & Bamboo \\
\hline Linear density, dtex & - & 1.3 & 1.3 & 1.3 & 1.3 \\
\hline $\begin{array}{l}\text { Staple/cut length, } \\
\text { mm }\end{array}$ & 27.3 & 38 & 39 & 39 & 38 \\
\hline $\begin{array}{l}\text { Breaking tenacity, } \\
\text { cN/tex }\end{array}$ & 27.9 & 36 & 35 & 25 & 21 \\
\hline $\begin{array}{l}\text { Elongation, \% } \\
\text { Moisture, \% }\end{array}$ & 6.6 & 14 & 13 & 20 & 17 \\
\hline Micronaire, $\mu \mathrm{g} /$ inch & 4.6 & - & - & - & - \\
\hline $\begin{array}{l}\text { Length uniformity, } \\
\%\end{array}$ & 83.6 & - & - & - & - \\
\hline Short fiber index & 33.4 & - & - & - & - \\
\hline Rd value & 73.3 & - & - & - & - \\
\hline +b value & 8.6 & - & - & - & - \\
\hline
\end{tabular}

\subsection{Methods}

\subsubsection{Yarn production}

Six yarn samples of linear density of 20 tex were produced with two different blending ratios, as given in Table 2.

The blending was done in the Blow-room and yarn samples were produced by employing conventional ring spinning technique. The detail of spinning machinery is given in Table 3.
Table 2. Blend ratios

\begin{tabular}{|l|c|}
\hline Yarns & Ratio \\
\hline Cotton & 100 \\
\hline Viscose & 100 \\
\hline Viscose:tencel & $50: 50$ \\
\hline Viscose:modal & $50: 50$ \\
\hline Viscose:bamboo & $50: 50$ \\
\hline Viscose:cotton & $50: 50$ \\
\hline
\end{tabular}

Table 3. Machinery for yarn manufacturing

\begin{tabular}{|c|c|c|}
\hline S. No. & Machine & Make \\
\hline 01 & Blow room & Rieter, Truzschler \\
\hline 02 & Card & MK-5 Crosrol \\
\hline 03 & Drawing frame & DX8, RSB D 30 \\
\hline 04 & Comber & Toyoda VC-5A \\
\hline 05 & Simplex & Toyota FL-16 \\
\hline 06 & Ring frame & Toyota RY-4 \\
\hline 07 & Auto winder & Muratec 21-c \\
\hline
\end{tabular}

\subsubsection{Fabric samples preparation}

Plain woven fabrics samples with Ends (76) and Picks (68) per inch of $120 \mathrm{gsm}$ were prepared on CCI loom (model SL 8900S) of Taiwan. The loom was with reed of 35, having speed 36 picks/min with 2 no. of ends per reed dent. The total no. of warp ends was 1120 and the prepared fabric had length of 55 and width of 15 inches.

\subsubsection{Fabric processing}

The sample fabrics were first desized (detail is given in Table 4) and then scoured and bleached (detail is given in Table 5).

Table 4. Desizing recipe and process conditions

\begin{tabular}{|l|c|}
\hline Parameters & Values \\
\hline Desizer & $5 \mathrm{~g} / \mathrm{L}$ \\
\hline Detergent & $2 \mathrm{~g} / \mathrm{L}$ \\
\hline Temperature & $40^{\circ} \mathrm{C}$ \\
\hline Time & 6 hours \\
\hline
\end{tabular}

Table 5. Scouring and bleaching recipe and process conditions

\begin{tabular}{|l|c|}
\hline Parameters & Values \\
\hline $\mathrm{NaOH} \mathrm{ml} / \mathrm{L}$ & 10 \\
\hline Stabilizer ml/L & 5 \\
\hline $\mathrm{H} 2 \mathrm{O} 2 \mathrm{ml} / \mathrm{L}$ & 35 \\
\hline Wetting agent g/L & 2 \\
\hline Temperature & $90{ }^{\circ} \mathrm{C}$ \\
\hline Time & $40 \mathrm{~min}$ \\
\hline
\end{tabular}

\subsubsection{Testing}

The fabric samples were tested for performance and comfort. Tensile strength of fabric samples was determined according to standard testing method ASTM D5035-11. Tear strength of fabric samples was determined by standard test method ASTM D1424-09(2013). Air permeability of each sample fabric was determined using standard testing method ASTM D737-04(2012) by Air permeability tester M-021A SDL Atlas, UK. Liquid moisture management properties of pre-treated and finished samples were determined with Moisture management tester M-290 SDL Atlas, UK using standard AATCC test method 195-2009. 
Thermal resistivity of fabric samples was determined by using standard test method ASTM D1518 - 11a with the help of Thermal resistivity tester M-259B SDL Atlas, UK.

\section{RESULTS AND DISCUSSION}

\subsection{Mechanical properties of yarns}

The results of breaking tenacity and associated elongations at break are plotted in Fig. 1. The highest strengths are given by viscose:modal and viscose:tencel blends as tencel (36 cN/tex) and modal (35 cN/tex) fibers have higher breaking tenacities. Viscose:bamboo gives better strength than viscose:cotton however lower than viscose:modal and viscose tencel. Viscose:cotton gives the lowest strength and elongation at break (\%) as the staple length and elongation at break of cotton fiber $(6.6 \%)$ is much lower than that of viscose $(20 \%)$ as cotton fibers are expected to reach the rupture point earlier and subsequently the entire yarn structure collapses as the remaining viscose fibers cannot withstand the already generated load. Statistical analysis (one-way ANOVA) shows that the strength of yarns of viscose and its blends have values significantly different as p-value is less than 0.05 .

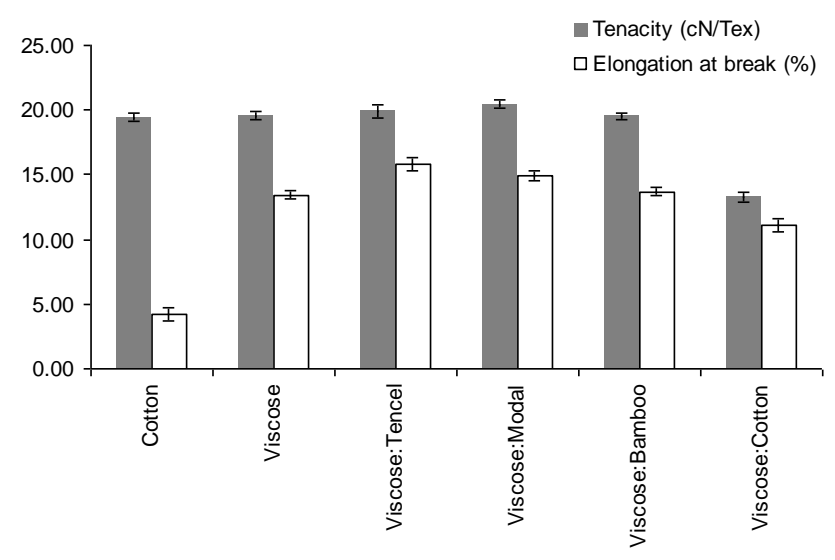

Fig. 1. Tensile properties of yarns

\subsection{Mechanical properties of fabrics}

\subsubsection{Tensile strength}

$100 \%$ cotton and viscose show equal tensile strength of fabrics. Viscose in blended form with tencel shows highest tensile strength when compared with its pure as well as blends with cotton, modal and bamboo as shown in Fig. 2 .

This is due to the high strength of tencel due to its highly crystalline structure $[4,13,14]$. Viscose itself has lesser crystallinity and more amorphous regions in structure, which makes it lack in the strength [14]. Viscose: modal blend shows less strength than viscose:tencel however it shows higher strength than viscose:bamboo and viscose:cotton. This is due to the higher strength of tencel and modal fibers than bamboo and cotton fibers. Statistical analysis (one-way ANOVA) shows that the tensile strength in warp and weft direction for viscose and its blends has values significantly different as p-value is less than 0.05 .

\subsubsection{Tear strength}

The maximum tear strength in both warp and weft directions is observed for $100 \%$ viscose fabric (Fig. 3).

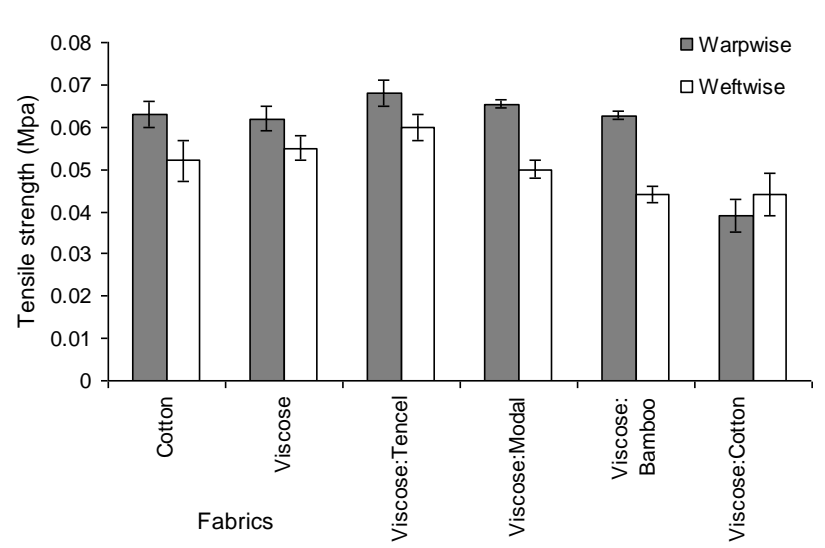

Fig. 2. Tensile strength of woven fabrics

Cotton: viscose blend is found to offer the least tear resistance in both warp and weft directions due to lower strength of cotton fibers. Viscose:tencel shows little drop in tear strength. Viscose: modal and viscose: bamboo blends also shows loss in tear strength in comparison to pure viscose. Tear strength mainly depends upon fiber, yarn and fabric characteristics. In case of fiber, strength and fineness are the parameters that decide the strength of yarn and ultimately fabric. Single yarn strength, elongation as well as twist are the strength deciding factors.

In case of fabric, type of weave and weight $/ \mathrm{m}^{2}$ contribute the strength [15]. In this research, yarn linear density and weave design were kept constant. In comparison of fabrics made of pure viscose and its blends with cotton and other regenerated blends show that viscose in pure form give higher strength as compared to its blends. Viscose:tencel blend gives less strength which might have been caused due to the brittleness occurred due to high twist multiplier of viscose:tencel blend but this blend has highest strength among all other blends of viscose with other fibers under observation.

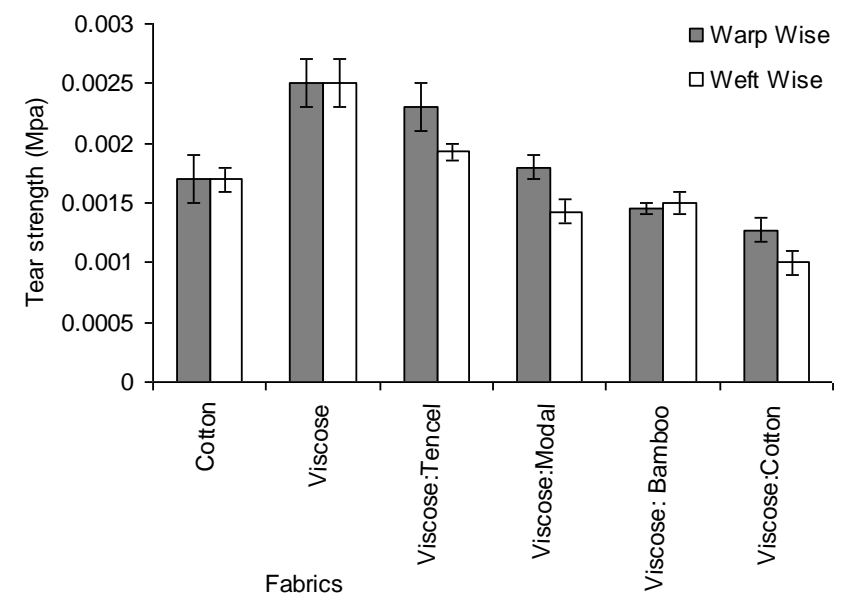

Fig. 3. Tear strength of woven fabrics

Yarn regularity is also a factor affecting tear strength. As more regularity in the yarn causes smoothness and helps slippage of yarn ends when they are subjected to shear loads [15], so, tear strength increases. Analyzing the yarn made from viscose:tencel blend shows that it has less regularity in comparison to pure viscose. Also, yarns made from 
viscose:modal and viscose:bamboo blends show less regularity in spite of high single yarn strength, tenacity and elongation. This might also be the reason that viscose gives the highest tear strength. Statistical analysis (one-way ANOVA) shows that the tear strength in warp and weft direction for viscose and its blends has values significantly different as p-value is less than 0.05 .

\subsection{Comfort properties}

\subsubsection{Air permeability}

Air-permeability is the one of most important comfort properties of cellulose fibers. For a woven fabric, yarn twist is an important factor. As twist increase, the yarn diameter and the cover factor are decreased. This increases air permeability. Increasing yarn twist may also make more circular and high-density yarns to be packed closely together in a tightly woven structure with reduced air permeability. Yarn flattening is another factor that affects the surface of fabric. Yarn is not ideally circular. When yarn is flattened down, it covers the spaces between the yarn ends in fabric and hence hinders the air passage through the fabric [16]. Fiber cross section also effects on the intra-yarn gaps, which further affects the fabric porosity [17]. Air permeability of woven fabrics' fiber cross section has impact on the porosity of the yarn [17] as the grooved/serrated [18] structures provide greater surface area as compared to circular cross-section. The greater surface area decreases the porosity of the material by decreasing the intra-yarn gaps [17], which might cause reduction of the passage of air leading to lower air-permeability. Moreover, the packing density of yarn being high might have increased the cover of the fabric thus leading to lower air-permeability [16].

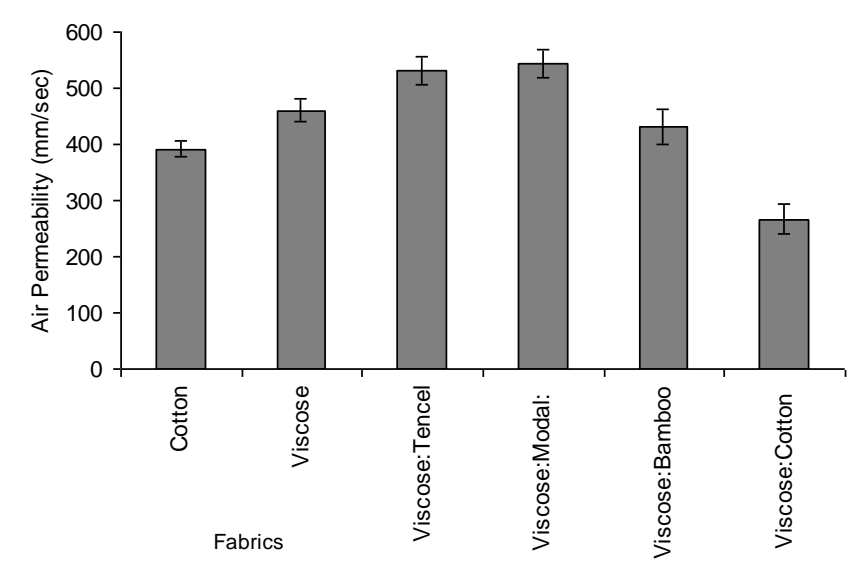

Fig. 4. Air permeability of woven fabrics

Modal has small pores and very large pores towards center [18]. So, visose:modal gives highest air permeability (Fig. 4). Visocse:tencel gives also gives better air permeability as shown in (Fig. 4). It is due to the fact that tencel has homogeneous distribution of pores in whole structure [18] which makes it to absorb and wick the moisture well and hence highly air permeable as water does not trap in pores and does not cause hindrance for air. As tencel fiber has circular shape, so, this might also increase in air permeability. Cotton and viscose in pure form shows less air permeability. Viscose also in pure form shows lower air-permeability value but its blends with modal and tencel boosts the performance (air permeability) of fabric. Statistical analysis (one-way ANOVA) shows that the air permeability for viscose and its blends has values significantly different as p-value is less than 0.05 .

\subsubsection{Moisture management}

Tencel: viscose blend is found to have the highest value of moisture management while viscose:bamboo blend is found to have the lowest value (Fig. 5). Blend of cotton with viscose shows higher value in comparison to $100 \%$ viscose. Blend of viscose and modal exceptionally shows decrease in moisture absorption. Viscose: bamboo blend is found to have slightly higher value as compared to viscose: modal blend.

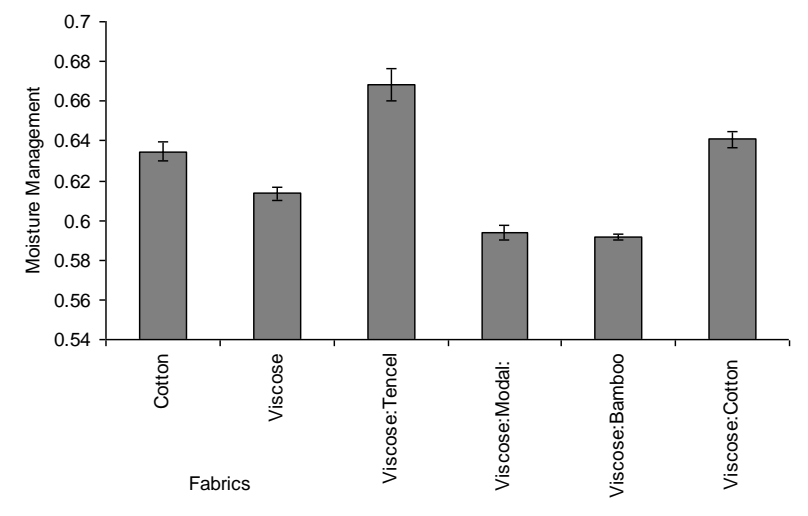

Fig. 5. Moisture management of woven fabrics

Tencel fiber is composed of structural subunits (fibrils) in micro and nanometer range. Different porous zones could be distinguished, partly confirming the crystallization model. The very first zones of the skin surface have a high porosity. A porous fiber middle zone is characterized by a gradually increase in the porosity. Pores and cellulose domains are presumably surrounding the cellulose bodies. It also ends gradually toward the compact fiber center, where the pores became tighter and the overall structure more compact [18]. This nano-structure of tencel made viscose:tencel blend having highest moisture mangemet properties among all viscose blends. Viscose itself has moisture absorption ability but it wicks less as compared to Tencel and modal [18]. A core/shell structure in Viscose fibers, corresponding with the already known structure of fibers produced through the viscose route - a dense shell and a porous, spongy core. Modal fibers show a compact external structure with very small pores and some large pores towards the center [18]. In this work, the blend of viscose and modal reveals a drop in the moisture absorption ability instead of high absorption ability of modal. This might have been the effect of increased twist level to impart strength in yarn which might have made modal to absorb less moisture giving lower moisture management properties.

Cotton also has moisture absorption ability. It contains lumen in the center which is left behind after the collapse of cell wall when fiber reaches its mature stage. Water absorption is aided by lumen. Lumen also helps cotton to wick by drawing water through capillary action thus making cotton a comfortable fiber [12]. Also, as Viscose has more 
amorphous regions giving more voids in its structure [18] that is why viscose:cotton blend also show better moisture management properties given in (Fig. 5).

As bamboo fiber has small gaps and voids in its structure which enables it to absorb moisture and by wicking through micro channels makes it a comfortable fiber [19], however; here, Viscose: bamboo gives less moisture management properties in comparison to all other blends. Statistical analysis (one-way ANOVA) shows that the moisture management for viscose and its blends has values significantly different as p-value is less than 0.05 .

\subsubsection{Thermal resistance}

The thermal resistance of all fabrics is shown in Fig. 6. Viscose in blend with tencel exhibits high thermal resistivity in comparison to blend with modal. $100 \%$ viscose is found to have least thermal resistivity value which means it conducts most when in pure form. Moreover, the effect is more enhanced when it is blended with bamboo. Blend of viscose with cotton in 50:50 ratio also give more value of thermal resistivity as compared to pure viscose.

Viscose exhibits higher thermal resistivity when blended with tencel. This might have been due to the nanostructure of tencel. The nano-fibrils in the structure help maintain the warmth by sensory control of the body by perfect moisture management of the fiber [20]. Thermal resistance is less enhanced when observed in case of viscose:modal. Viscose:bamboo blend less thermal resistivity. This might have been due to the lower wicking of bamboo and viscose in comparison to modal and tencel.

In case of cotton, molecules are long, twisted chains of cellulose, composed of glucose molecules. As the chains twist around one another, they leave spaces that hold air. When fibers composed of these long molecules are woven into cloth, they twist further, holding more air. These pockets of air each capture heat from the body and retard its radiation into a cooler environment [18].

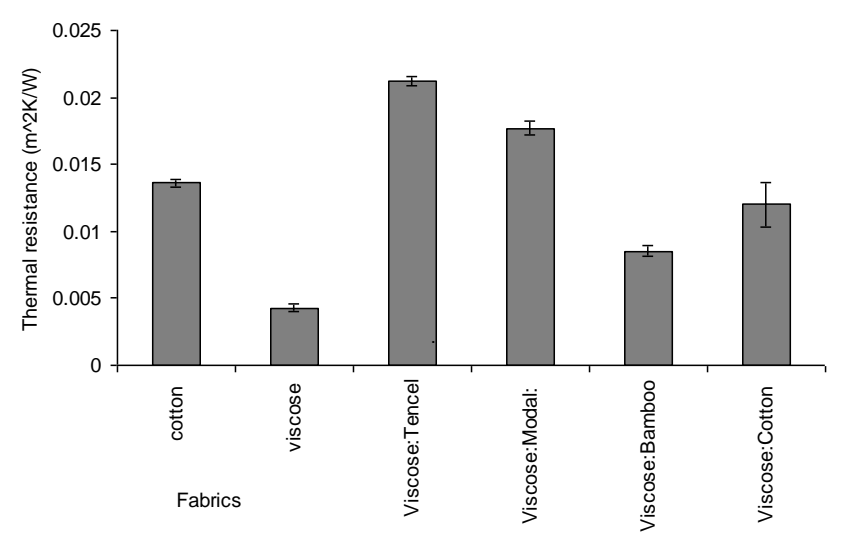

Fig. 6. Thermal resistance of woven fabrics

Hence, Viscose:cotton gives an enhanced effect in thermal resistance due to insulation properties of cotton. Moreover, Statistical analysis (one-way ANOVA) shows that the thermal resistance for viscose and its blends has values significantly different as p-value is less than 0.05 .

\section{CONCLUSION}

In this work, $100 \%$ woven fabrics of cotton and viscose were made. Moreover, 50:50 blended fabrics of viscose with tencel, modal, bamboo and cotton were prepared. The mechanical and comfort properties were studied and compared. It is found that the viscose:tencel and viscose:modal blend gives the best mechanical and comfort properties than all other blends. Also, it is found that viscose:cotton and viscose:bamboo blend gives the lowest mechanical and comfort properties out of all studied fabrics. Therefore, it can be concluded that viscose when blended with tencel and modal give better properties than $100 \%$ cotton, $100 \%$ viscose and the other studied blends; hence, viscose:tencel and viscose:modal being the sustainable blends can replace $100 \%$ cotton in clothing applications.

\section{REFERENCES}

1. The Deadly Chemicals in Cotton (23/06/2017) available: http://ejfoundation.org/report/deadlychemicals-cotton

2. Kramer, S.B., $\quad$ Reganold, J.P., $\quad$ Glover, J.D., Bohannan, B.J., Mooney, H.A. Reduced Nitrate Leaching and Enhanced Denitrifier Activity and Efficiency in Organically Fertilized Soils Proceedings of the National Academy of Sciences of the United States of America 103 (12) 2006: pp. 4522 - 4527. https://doi.org/10.1073/pnas.0600359103

3. Kayseri, G.O., Bozdogan, F., Hes, L. Performance Properties of Regenerated Cellulose Fibers Tekstil ve Konfeksiyon 20 (3) 2010: pp. 208-212.

4. Carrillo, F., Colom, X., Sunol, J., Saurina, J. Structural FTIR Analysis and Thermal Characterisation of Lyocell and Viscose-Type Fibres European Polymer Journal 40 (9) 2004: pp. 2229-2234. https://doi.org/10.1016/j.eurpolymj.2004.05.003

5. Woodings, C. Regenerated Cellulose Fibres: Woodhead Publishing, 2001. https://doi.org/10.1533/9781855737587

6. Çinçik, E., Koç, E. An Analysis on Air Permeability of Polyester/Viscose Blended Needle-Punched Nonwovens Textile Research Journal 82 (5) 2012: pp. $430-442$. https://doi.org/10.1177/0040517511414977

7. Varshney, R., Kothari, V., Dhamija, S. A Study on Thermophysiological Comfort Properties of Fabrics in Relation To Constituent Fibre Fineness and CrossSectional Shapes The Journal of The Textile Institute 101 (6) 2010: pp. 495 - 505. https://doi.org/10.1080/00405000802542184

8. Tausif, M., Ahmad, F., Hussain, U., Basit, A., Hussain, T. A Comparative Study of Mechanical and Comfort Properties of Bamboo Viscose as an EcoFriendly Alternative to Conventional Cotton Fibre in Polyester Blended Knitted Fabrics Journal of Cleaner Production 89 2015: pp. 110-115. https://doi.org/10.1016/j.jclepro.2014.11.011

9. Öner, E., Atasağun, H., Okur, A., Beden, A., Durur, G. Evaluation of Moisture Management 
Properties on Knitted Fabrics Journal of the Textile Institute 104 (7) 2013: pp. 699-707.

https://doi.org/10.1080/00405000.2012.752895

10. Mishra, R., Behera, B., Pada Pal, B. Novelty of Bamboo Fabric Journal of the Textile Institute 103 (3) 2012: pp. 320-329.

11. Cimilli, S., Nergis, B., Candan, C., Özdemir, M. A Comparative Study of Some Comfort-Related Properties of Socks of Different Fiber Types Textile Research Journal 80 (10) 2010: pp. 948-957. https://doi.org/10.1177/0040517509349782

12. Gun, A.D. Dimensional, Physical and Thermal Properties of Plain Knitted Fabrics Made From 50/50 Blend of Modal Viscose Fiber in Microfiber Form With Cotton Fiber Fibers and Polymers 12 (8) 2011: pp. $1083-1090$. https://doi.org/10.1007/s12221-011-1083-3

13. Kreze, T., Malej, S. Structural Characteristics of New and Conventional Regenerated Cellulosic Fibers Textile Research Journal 73 (8) 2003: pp. 675-684. https://doi.org/10.1177/004051750307300804

14. Stana-Kleinschek, K., Ribitsch, V., Kreže, T., Sfiligoj-Smole, M., Peršin, $Z$. Correlation of Regenerated Cellulose Fibres Morphology and Surface Free Energy Components Lenzinger Berichte 82 (1) 2003: pp. $83-95$.
15. Dhamija, S., Chopra, M. Tearing Strength of Cotton Fabrics in Relation to Certain Process and Loom Parameters Indian Journal of Fibers \& Textile Research 32 (4) 2007: pp. 439-445.

16. Kullman, R.M.,

Graham, J.R.C.O., Ruppenicker, G.F. Air permeability of Fabrics made from unique and Conventional yarns Textile Research Journal 51 (12) 1981: pp. 781-786. https://doi.org/10.1177/004051758105101207

17. Tascan, M., Vaughn, E.A. Effects of Fiber Denier, Fiber Cross-Sectional Shape and Fabric Density on Acoustical Behavior of Vertically Lapped Nonwoven Fabrics Journal of Engineered Fibers and Fabrics 3 (2) 2008: pp. 32-38.

18. Abu-Rous, M., Ingolic, E., Schuster, K. Visualisation of the Nano-Structure of Tencel®(Lyocell) and Other Cellulosics as an Approach to Explaining Functional and Wellness Properties in Textiles Lenzinger Berichte 85 2006: pp. 31-37.

19. Erdumlu, N., Ozipek, B. Investigation of Regenerated Bamboo Fibre and Yarn Characteristics Fibres \& Textiles in Eastern Europe 16 (4) 2008: pp. 43-47.

20. Männer, J., Schuster, K.C., $\quad$ Suchomel, F., Gürtler, A., Firgo, H. Higher Performance with Natural Intelligence Lenzinger Berichte 83 2004: pp. $99-110$. 